\title{
$\alpha$-Lithiated Aryl Benzyl Ethers: Inhibition of [1,2]-Wittig Rear- rangement and Application to the Synthesis of Benzo[b]furan Derivatives
}

\author{
Rocío Velasco, Claudia Feberero, and Roberto Sanz* \\ Área de Química Orgánica, Departamento de Química, Facultad de Ciencias, Universidad de Burgos, Pza. Misael Bañuelos \\ $\mathrm{s} / \mathrm{n}$, 09001-Burgos, Spain \\ Supporting Information Placeholder
}

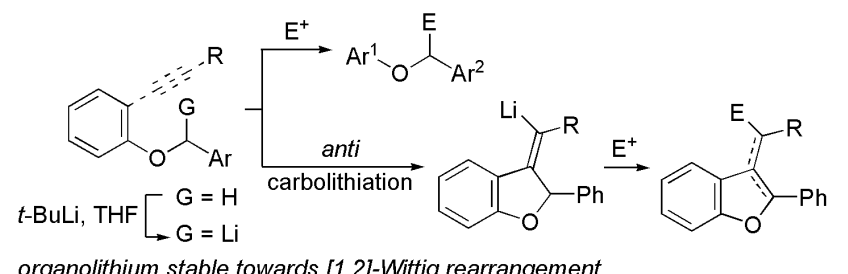

organolithium stable towards [1,2]-Wittig rearrangement

ABSTRACT: The use of $t$-BuLi at low temperature selectively leads to $\alpha$-lithiation of benzyl phenyl ether generating a stable organolithium, which can be efficiently trapped with a variety of selected electrophiles prior to suffering the expected [1,2]-Wittig rearrangement. In the case of (o-alkynyl)phenyl benzyl ethers, the intermediate $\alpha$-aryloxyorganolithium undergoes an unexpected anti intramolecular carbolithiation reaction leading to functionalized benzo $[b]$ furan derivatives.

$\alpha$-Alkoxyorganolithiums, usually generated by deprotonation of ethers ${ }^{1}$ or by $\mathrm{Sn}-\mathrm{Li}$ exchange, ${ }^{2}$ are generally unstable undergoing either elimination or Wittig rearrangements. ${ }^{3}$ For the $[1,2]$ variant of the Wittig rearrangement, ${ }^{4}$ the use of allyl or benzyl ethers allows the migrating group to be benzylic, secondary or primary alkyl, but not methyl. This reluctance of the methyl group to undergo migration has allowed the trapping of $\alpha$-lithiobenzyl methyl ether with electrophiles. ${ }^{5}$ In this context, it would be highly interesting to find a way to avoid the Wittig rearrangement and allow functionalization of other $\alpha$-lithiobenzyl ethers. The most accepted mechanism for the [1,2]-Wittig rearrangement is a two-stage process that involves the homolysis of the $\alpha$-anion intermediate and subsequent recombination of the radical and radical anion fragment. This proposal mainly satisfies the observed migratory aptitude for the $\mathrm{R}^{1}$ groups (Scheme 1, eq 1). However, the migration of aryl groups from aryl benzyl ethers has received much less attention (Scheme 1 , eq 2$)^{6}$

Our interest in this field ${ }^{7}$ led us to report that $\alpha$-lithiobenzyl $o$-lithiophenyl ethers, generated from benzyl 2-halophenyl ethers, do not undergo Wittig rearrangement probably due to the reluctance of the $o$-lithiophenoxy ring to migrate (Scheme 1, eq 3). ${ }^{8}$ At this point, we thought about the possibility of inhibiting the Wittig rearrangement from aryl $\alpha$-lithiobenzyl ethers without the requirement of the additional lithium atom at the aryl ring. With all these results in mind, and considering the unexplored potential synthetic usefulness of aryl $\alpha$ lithiobenzyl ethers, ${ }^{9}$ we proposed to study the $\alpha$-lithiation of aryl benzyl ethers with the aim of finding suitable conditions in which these anionic intermediates were stable enough to avoid the Wittig rearrangement (Scheme 1). In this paper, we wish to report the successful generation of $\alpha$-lithiated aryl benzyl ethers and their functionalization with selected electrophiles, including intramolecular anti carbolithiation reactions onto unactivated $\mathrm{C}-\mathrm{C}$ triple bonds to generate benzo[b]furan derivatives.

Scheme 1. Previous Work and Proposed $\alpha$-Lithiation of Aryl Benzyl Ethers

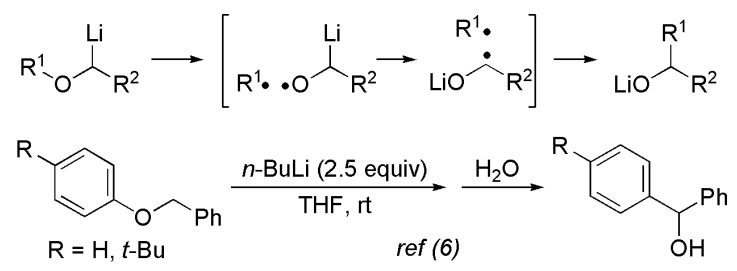

Our previous work:

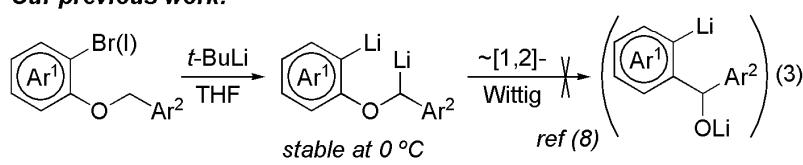

This work: 
We selected benzyl phenyl ether 1a as model substrate and performed the metalation reaction under the conditions reported by Eisch et al. As expected, a complete conversion to diphenylmethanol 3a takes place by using BuLi at $0{ }^{\circ} \mathrm{C}$, in agreement with their results (Scheme 2). ${ }^{6 a}$ In order to generate the lithiated intermediate $2 \mathbf{a}$ at a lower temperature, we decided to use a stronger base ( $t$-BuLi). Gratifyingly, deuteriated ether 4a was selective and almost quantitatively obtained by reacting 1a with a slight excess of $t$-BuLi at $-78{ }^{\circ} \mathrm{C}$ (Scheme 2 ). This result shows that simply by decreasing the temperature, the $[1,2]$-Wittig rearrangement can be suppressed. We also studied the stability of intermediate $\alpha$ alkoxyorganolithium 2a by gradually increasing the reaction temperature, finding that the [1,2]-Wittig rearrangement initiates at ca. $-30{ }^{\circ} \mathrm{C}$ (Scheme 2). In addition, when the lithiation reaction of 1a was carried out in $\mathrm{Et}_{2} \mathrm{O}$, it was not until $-30{ }^{\circ} \mathrm{C}$ that complete lithiation took place, implying that in this solvent organolithium 2a is stable at higher temperatures than when using THF. ${ }^{10}$ With this study we have shown how 1a can be efficient and selectively lithiated at low temperature in THF to generate organolithium intermediate $\mathbf{2 a}$, which remains stable up to ca. $-30{ }^{\circ} \mathrm{C}$.

\section{Scheme 2. $\alpha$-Lithiation of Benzyl Phenyl Ether 1a}

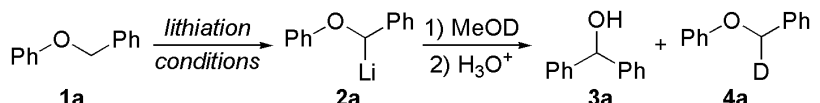

$$
\begin{aligned}
& n \text {-BuLi (2.5 equiv), THF, } 0^{\circ} \mathrm{C}, 90 \mathrm{~min} \quad 1 / 0 \\
& t \text {-BuLi (1.3 equiv), THF, }-78^{\circ} \mathrm{C}, 20 \mathrm{~min} \quad 0 / 1 \\
& t \text {-BuLi (1.3 equiv), THF, }-30^{\circ} \mathrm{C}, 20 \mathrm{~min} \quad 1 / 15
\end{aligned}
$$

These optimized lithiation conditions were used to prepare a variety of $\alpha$-functionalized aryl benzyl ethers 5aa-5ak after electrophilic quenching (Table 1, entries 2-12). Addition of alkyl halides gave high yields of the corresponding $\alpha$ alkylated ethers (entries 2 and 3). In the same way, the use of $\mathrm{TMSCl}$ or $\mathrm{Bu}_{3} \mathrm{SnCl}$ resulted in the production of functionalized ethers 5ac and 5ad (entries 4 and 5). Typical carbonyl electrophiles such as aldehydes (entries 6 and 7) and ketones (entries 8-10) gave the corresponding hydroxyl-functionalized ethers in high yields. The process was also amenable to an imine or an epoxide as electrophiles, giving rise to products 5aj and 5ak respectively (entries 11 and 12). In all cases, when two stereogenic centers are generated, the final compound is obtained as a variable mixture of diastereoisomers.

We have also investigated the metalation and functionalization of other aryl benzyl ethers 1b-e related to the parent benzyl phenyl ether 1a. Benzyl ethers 1b,c bearing a chloro or a methoxy substituent at para position of the aryl moiety undergo selective benzylic deprotonation on treatment with $t$-BuLi, and the corresponding $\alpha$-lithiated species $\mathbf{2 b , \mathbf { c }}$ can be trapped with selected electrophiles (entries 13-16). In the same way, starting ethers 1d,e substituted at para position of the benzylic moiety were also tried and the corresponding $\alpha$-deuteriated or $\alpha$-functionalized benzyl ethers $\mathbf{4}$ and $\mathbf{5}$ were obtained (entries 17-20). Only with ether 1e, possessing a 4-methoxybenzyl group a significant increase in the reaction temperature was required to reach an almost complete lithiation. ${ }^{11}$ This fact is likely due to the lower acidity of the benzylic hydrogen imposed by the $p$-methoxy group.
Table 1. Reaction of Aryl $\alpha$-Lithiobenzyl Ethers 2 with Electrophiles. Synthesis of Funtionalized Ethers 5

\begin{tabular}{|c|c|c|c|c|c|c|}
\hline entry & 1 & $\mathrm{R}^{1}$ & $\mathrm{R}^{2}$ & 4,5 & $\mathrm{E}$ & $\begin{array}{l}\text { yield } \\
(\%)^{a}\end{array}$ \\
\hline 1 & $1 \mathbf{a}$ & $\mathrm{H}$ & $\mathrm{H}$ & $4 a$ & $\mathrm{D}$ & 96 \\
\hline 2 & $1 \mathbf{a}$ & $\mathrm{H}$ & $\mathrm{H}$ & 5 aa & $\mathrm{Me}$ & 95 \\
\hline 3 & $1 \mathbf{a}$ & $\mathrm{H}$ & $\mathrm{H}$ & 5 ab & $\mathrm{CH}_{2} \mathrm{CH}=\mathrm{CH}_{2}$ & 88 \\
\hline 4 & $1 \mathbf{a}$ & $\mathrm{H}$ & $\mathrm{H}$ & 5 ac & $\mathrm{SiMe}_{3}$ & 95 \\
\hline 5 & $1 \mathrm{a}$ & $\mathrm{H}$ & $\mathrm{H}$ & 5 ad & $\mathrm{SnBu}_{3}$ & 62 \\
\hline 6 & 1a & $\mathrm{H}$ & $\mathrm{H}$ & $5 \mathbf{a e}^{b}$ & $\mathrm{CH}(\mathrm{OH})\left(4-\mathrm{ClC}_{6} \mathrm{H}_{4}\right)$ & 79 \\
\hline 7 & 1a & $\mathrm{H}$ & $\mathrm{H}$ & $5 \mathbf{a f}^{c}$ & $\mathrm{CH}(\mathrm{OH}) i-\mathrm{Pr}$ & 71 \\
\hline 8 & $1 \mathbf{a}$ & $\mathrm{H}$ & $\mathrm{H}$ & $5 a g$ & $\mathrm{C}(\mathrm{OH}) \mathrm{Ph}_{2}$ & 81 \\
\hline 9 & $1 \mathbf{a}$ & $\mathrm{H}$ & $\mathrm{H}$ & $\mathbf{5 a h}^{d}$ & $\mathrm{C}(\mathrm{OH}) \mathrm{PrPh}$ & 78 \\
\hline 10 & 1a & $\mathrm{H}$ & $\mathrm{H}$ & $5 \mathbf{a i}^{e}$ & $\mathrm{C}(\mathrm{OH})(2-\mathrm{Th}) c-\mathrm{C}_{3} \mathrm{H}_{5}$ & 79 \\
\hline 11 & 1a & $\mathrm{H}$ & $\mathrm{H}$ & $5 \mathbf{a j}^{b}$ & $\mathrm{CH}(\mathrm{Ph}) \mathrm{NHPh}$ & 65 \\
\hline 12 & 1a & $\mathrm{H}$ & $\mathrm{H}$ & $\mathbf{5} \mathbf{a} \mathbf{k}^{f}$ & $\mathrm{CH}-\left(\mathrm{CH}_{2}\right)_{4} \mathrm{CH}(\mathrm{OH})-$ & 95 \\
\hline 13 & $1 b$ & $\mathrm{Cl}$ & $\mathrm{H}$ & $4 b$ & $\mathrm{D}$ & 97 \\
\hline 14 & $1 b$ & $\mathrm{Cl}$ & $\mathrm{H}$ & $5 \mathbf{b a}^{b}$ & $\mathrm{CH}(\mathrm{OH}) i-\mathrm{Pr}$ & 83 \\
\hline 15 & 1c & $\mathrm{OMe}$ & $\mathrm{H}$ & $4 c$ & $\mathrm{D}$ & 90 \\
\hline 16 & 1c & $\mathrm{OMe}$ & $\mathrm{H}$ & $5 \mathbf{c a}{ }^{f}$ & $\mathrm{CH}-\left(\mathrm{CH}_{2}\right)_{4} \mathrm{CH}(\mathrm{OH})-$ & 88 \\
\hline 17 & 1d & $\mathrm{H}$ & $\mathrm{Cl}$ & 4d & $\mathrm{D}$ & 94 \\
\hline 18 & 1d & $\mathrm{H}$ & $\mathrm{Cl}$ & $5 d a$ & Et & 92 \\
\hline 19 & $1 \mathrm{e}^{g}$ & $\mathrm{H}$ & $\mathrm{OMe}$ & $4 e^{h}$ & $\mathrm{D}$ & 93 \\
\hline 20 & $1 \mathbf{e}^{g}$ & $\mathrm{H}$ & $\mathrm{OMe}$ & 5ea & $\mathrm{C}(\mathrm{OH}) \mathrm{Ph}_{2}$ & 70 \\
\hline
\end{tabular}

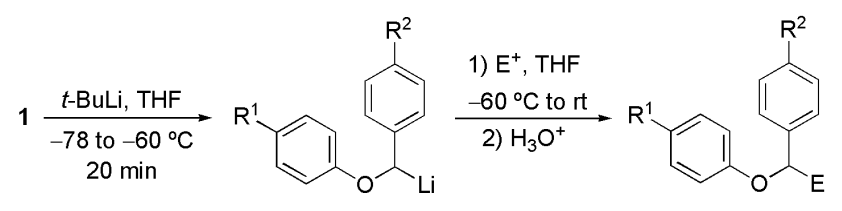

2

${ }^{a}$ Yield of isolated product referred to starting ether $1 .{ }^{b}$ Obtained as a 1:1 mixture of diastereoisomers. ${ }^{c}$ Obtained as a 1.25:1 mixture of diastereoisomers. The major one could be isolated in pure form. ${ }^{d}$ Obtained as 4:1 mixture of diastereoisomers. ${ }^{e}$ Obtained as 3.3:1 mixture of diastereoisomers. ${ }^{f}$ Cyclohexene oxide as electrophile. 5ak and 5ca were obtained as a ca. 1.5:1 mixture of diastereoisomers. ${ }^{g}$ Lithiation was carried out from -78 to $-35^{\circ} \mathrm{C}$. ${ }^{h} \sim 92 \%$-D incorporation.

Surprisingly, when ethyl benzoate was tested as electrophile, the aromatic ketone $\mathbf{6 a}$ was selectively obtained instead of the expected tertiary alcohol and independently of the amount of the ester added to $2 a$. This result was general for a selection of esters derived from aromatic acids, allowing the synthesis of ketones 6 in good yields (Scheme 3, eq 1). ${ }^{12}$ To account for this unexpected result, we propose that the initially formed ketone 6 undergoes deprotonation by the lithium ethoxide generated in the first step, leading to the corresponding enolate 7, which remains intact prior to hydrolysis. Our proposal was supported by the fact that, upon addition of methyl iodide, prior to aqueous workup, ketone 8 bearing a $\alpha$ quaternary center was isolated (Scheme 3, eq 2). Moreover, the addition of ethyl chloroformate as the electrophilic partner 
afforded $\alpha, \alpha^{\prime}$-difunctionalized ketone 9 as a 2:1 mixture of diastereoisomers in high yield (Scheme 3, eq 3). Interestingly, this ketone was always selectively obtained irrespective of the stoichiometry of the reactants.

Scheme 3. Reaction of $\alpha$-Lithiobenzyl Phenyl Ether 2a with Caboxylic Esters. Synthesis of Ketones 6, 8, and 9

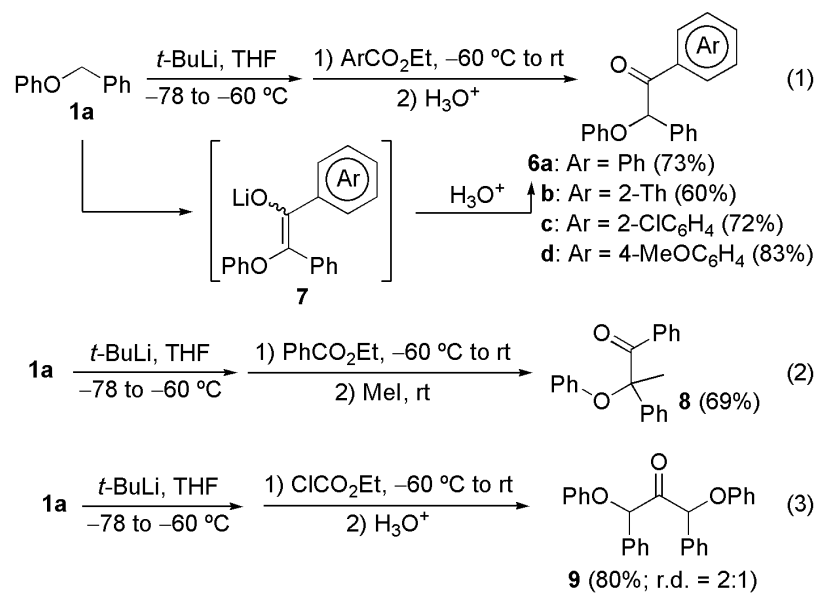

Due to the interest of benzo[b]furan derivatives, a wide variety of approaches for their synthesis have been reported. ${ }^{13}$ One of the most useful methodologies involves the intramolecular cyclization of $o$-(alkynyl)phenyl ethers or $o$ alkynylphenols by formation of a $\mathrm{C}-\mathrm{O}$ bond. Several transition metal-catalyzed or base-mediated processes have been described along the last years (Scheme 4, eq 1). ${ }^{14}$ However, just a few reports for accessing the benzo[b]furan skeleton have appeared involving the $\mathrm{C} 2-\mathrm{C} 3$ bond formation as an alternative methodology. ${ }^{15}$ Most of them are related to basemediated or catalyzed cyclizations of o-(alkynyl)phenyl benzyl ethers. Although this transition metal-free approach is highly interesting, developed procedures do not allow further functionalization of the generated benzofuran derivative thus, representing a drawback of these methodologies (Scheme 4, eq 2). ${ }^{16}$ Taking advantage from the easy and efficient lithiation that we had developed, we envisaged that an $\alpha$-lithiated $o$ (alkynyl)phenyl benzyl ether could undergo an intramolecular carbolithiation $^{17}$ giving rise to a new organolithium intermediate, which could be further functionalized with electrophiles (Scheme 4, eq 3).

Scheme 4. Intramolecular Cyclization of o-Alkynylphenyl Ethers and Proposed Intramolecular Carbolithiation

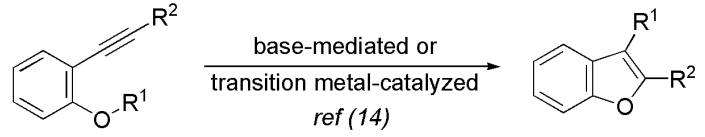

$\mathrm{R}^{1}=\mathrm{H}$, allyl, Bn,...
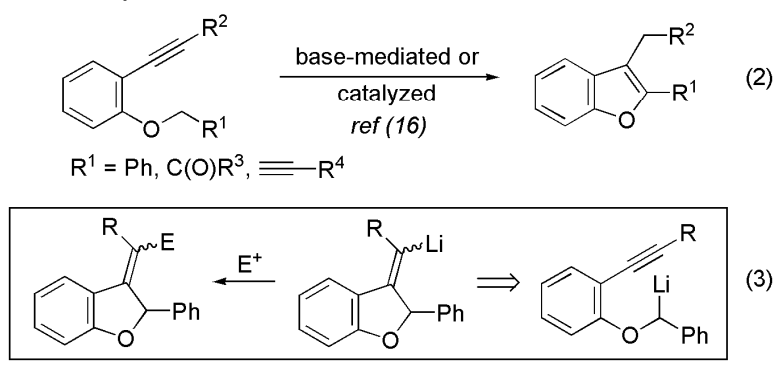

o-(Alkynyl)phenyl benzyl ether 10a was the chosen model to initiate the study of the proposed intramolecular carbolithiation reaction. In this case, it was necessary to raise the temperature to $-20{ }^{\circ} \mathrm{C}$ in order to complete lithiation at the $\alpha$-position and subsequent cyclization, obtaining product 12aa as a mixture of geometrical isomers (Scheme 5). When performing this optimization study, ${ }^{18}$ we noticed that deuteriated 10a at the $\alpha$-position was never obtained, which demonstrates that the lithiation is slower than the carbolithiation reaction. Based on previous reports about the cyclization of acetylenic organolithiums, ${ }^{19}$ the addition of the $\mathrm{C}-\mathrm{Li}$ unit to the triple bond to produce a 5-membered ring was expected to proceed in a syn fashion and, depending on the stability of the formed vinyllithium, it could undergo a cis-trans isomerization afterwards. Unsurprisingly, compound 12aa was obtained as a mixture of $Z$ and $E$-isomers. However, alkyl-substituted vinyllithiums are known to be configurationally stable, so the isolation of deuteriated dihydrobenzofuran $\mathbf{1 2 b a}$ as a single geometrical Z-isomer was really unexpected, meaning that an anti addition of the $\mathrm{C}-\mathrm{Li}$ bond to the alkyne had taken place, in the former case as well. ${ }^{20}$ Furthermore, benzyl ether 10c, bearing a cyclohex-1-enyl substituent, also undergoes an anti addition, although without complete selectivity, probably due to the configurational instability of the resulting vinyllithium, as in the case of the phenyl substituent (Scheme 5). Although an anti carbolithiation of propargyl $o$-lithioaryl ethers has been reported, ${ }^{21}$ in that specific case an interaction of a heteroatom located at the terminal position of the alkyne with the lithium atom seems to be the cause for the observed anti addition. ${ }^{22}$

On the other hand, we also checked that by raising the reaction temperature to $\mathrm{rt}$, the intermediate organolithium 11a $(\mathrm{R}=$ $\mathrm{Ph}$ ) smoothly undergoes isomerization giving rise to the deuteriated benzofuran derivative14aa after deuteriolysis in high yield (Scheme 5). ${ }^{23}$

Scheme 5. Intramolecular anti-Carbolithiation of o(Alkynyl)aryl Benzyl Ethers 10 


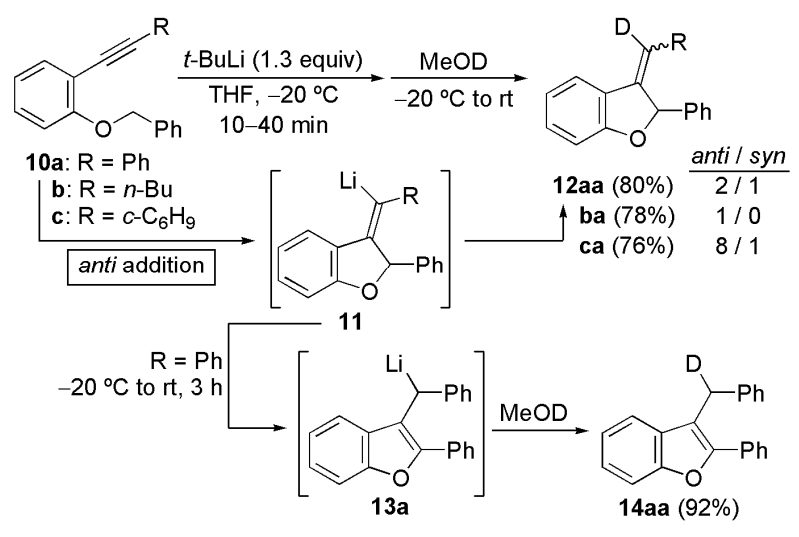

To further demonstrate the utility of this new carbolithiation reaction in the synthesis of benzofuran derivatives, a variety of representative electrophiles were used for trapping the intermediate organolithiums 11 or 13a (Table 2). Functionalized dihydrobenzofurans $\mathbf{1 2}$ were obtained in average to good yields as mixtures of geometrical isomers except in the case of 12bb bearing $\mathrm{R}=n$-Bu (entries $1-5$ ). The scope of the reaction was further explored by synthesizing a selection of 3benzyl-2-arylbenzo[b]furan derivatives 14ab-ag using different electrophiles (entries 6-11).

Table 2. Synthesis of Benzo[b]furan Derivatives 12 and 14

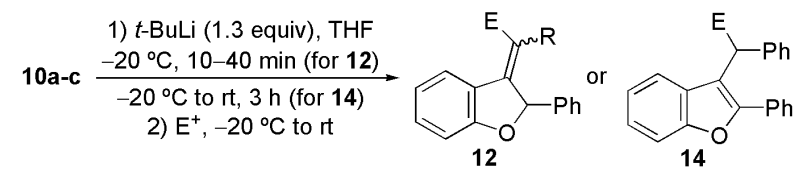

\begin{tabular}{|c|c|c|c|c|c|c|}
\hline entry & 10 & $\mathrm{R}$ & $\mathrm{E}^{+}$ & prod. & $\mathrm{E}$ & $\begin{array}{l}\text { yield } \\
(\%)^{a}\end{array}$ \\
\hline 1 & 10a & $\mathrm{Ph}$ & $\mathrm{I}_{2}$ & $12 \mathbf{a b}^{b}$ & I & 86 \\
\hline 2 & $10 a$ & $\mathrm{Ph}$ & $\mathrm{Me}_{3} \mathrm{SiCl}$ & $12 \mathbf{a c}^{b}$ & $\mathrm{SiMe}_{3}$ & 84 \\
\hline 3 & $10 a$ & $\mathrm{Ph}$ & $\mathrm{Me}_{3} \mathrm{SnCl}$ & 12ad $^{b}$ & $\mathrm{SnMe}_{3}$ & 80 \\
\hline 4 & 10b & $n-\mathrm{Bu}$ & $4-\mathrm{ClC}_{6} \mathrm{H}_{4} \mathrm{CHO}$ & $12 \mathbf{b} \mathbf{b}^{c}$ & $\mathrm{C}(\mathrm{H}) \mathrm{OH}\left(4-\mathrm{ClC}_{6} \mathrm{H}_{4}\right)$ & 71 \\
\hline 5 & 10c & $c-\mathrm{C}_{6} \mathrm{H}_{9}$ & $\mathrm{Me}_{2} \mathrm{CO}$ & $12 \mathbf{c b}^{d}$ & $\mathrm{C}(\mathrm{OH}) \mathrm{Me}_{2}$ & 70 \\
\hline 6 & $10 a$ & $\mathrm{Ph}$ & $\mathrm{Me}_{3} \mathrm{SiCl}$ & $14 a b$ & $\mathrm{SiMe}_{3}$ & 72 \\
\hline 7 & $10 a$ & $\mathrm{Ph}$ & $\mathrm{CH}_{2}=\mathrm{CHCH}_{2} \mathrm{Br}$ & $14 a c$ & $\mathrm{CH}_{2} \mathrm{CH}=\mathrm{CH}_{2}$ & 85 \\
\hline 8 & $10 a$ & $\mathrm{Ph}$ & $\mathrm{Me}_{2} \mathrm{CO}$ & 14ad & $\mathrm{C}(\mathrm{OH}) \mathrm{Me}_{2}$ & 82 \\
\hline 9 & $10 a$ & $\mathrm{Ph}$ & $\mathrm{PhCHO}$ & $14 \mathbf{a e}^{c}$ & $\mathrm{CH}(\mathrm{OH}) \mathrm{Ph}$ & 70 \\
\hline 10 & $10 a$ & $\mathrm{Ph}$ & $\mathrm{ClCO}_{2} \mathrm{Et}$ & 14af & $\mathrm{CO}_{2} \mathrm{Et}$ & 60 \\
\hline 11 & $10 a$ & $\mathrm{Ph}$ & $(p-\mathrm{TolS})_{2}$ & $14 a g$ & $\mathrm{~S}(p-\mathrm{Tol})$ & 78 \\
\hline
\end{tabular}

${ }^{a}$ Yield of isolated product after column chromatography referred to starting ether 10. ${ }^{b}$ Obtained as a ca. 1.2-2:1 mixture of geometrical isomers. ${ }^{c}$ Obtained as a mixture of diastereoisomers. ${ }^{d}$ Obtained as ca. 1:1 mixture of geometrical isomers.

In summary, easily available aryl benzyl ethers have been shown to be selectively $\alpha$-lithiated at low temperature, being stable enough to avoid the expected [1,2]-Wittig rearrangement. The $\alpha$-aryloxy benzyllithiums generated can be trapped with a wide range of electrophiles. Starting from $o$ (alkynyl)phenyl benzyl ethers, an intramolecular carbolithiation is triggered after $\alpha$-lithiation providing a direct entry to functionalized 2-arylbenzo[ $b]$ furan derivatives. More- over, the addition takes place in an unexpected anti fashion representing the first example of an anti carbolithiation of an unactivated triple bond without coordination of the lithium cation and the terminal substituent of the alkyne.

\section{ASSOCIATED CONTENT}

\section{Supporting Information}

Full experimental procedures, characterization data, and copies of NMR spectra. This material is available free of charge via the Internet at http://pubs.acs.org.

\section{AUTHOR INFORMATION}

\section{Corresponding Author}

*E-mail: rsd@ubu.es

Notes

The authors declare no competing interest.

\section{ACKNOWLEDGMENT}

We are grateful to the Junta de Castilla y León (BU237U13) and Ministerio de Economía y Competitividad (MINECO) and FEDER (CTQ2013-48937-C2-1-P) for financial support. R.V. thanks Junta de Castilla y León (Consejería de Educación) and Fondo Social Europeo for a PIRTU contract.

\section{REFERENCES}

(1) Wittig, G.; Löhmann, L. Justus Liebigs Ann. Chem. 1942, 550, 260-268.

(2) Sawyer, J. S.; Kucerovy, A.; Macdonald, T. L.; McGarvey, G. J. J. Am. Chem. Soc. 1988, 110, 842-853.

(3) (a) Marshall, J. A. The Wittig Rearrangement. In Comprehensive Organic Synthesis; Trost, B. M., Fleming, I., Eds.; Pergamon Press: Oxford, 1991; Vol. 3, pp 975-1014. (b) Schölkopf, U. Angew. Chem. Int. Ed. 1970, 9, 763-773. (c) Garst, J. F.; Smith, C. D. J. Am. Chem. Soc. 1976, 98, 1526-1537.

(4) (a) Tomooka, K.; Yamamoto, H.; Nakai, T. Liebigs Ann./Recueil 1997, 1275-1281. For selected synthetic applications, see: (b) Tomooka, K.; Yamamoto, K.; Nakai, T. Angew. Chem. Int. Ed. 1999, 38, 3741-3743. (c) Nakano, T.; Soeta, T.; Endo, K.; Inomata, K.; Ukaji, Y. J. Org. Chem. 2013, 78, 12654-12661.

(5) Azzena, U.; Demartis, S.; Fiori, M. G.; Melloni, G.; Pisano, L. Tetrahedron Lett. 1995, 31, 5641-5644.

(6) (a) Eisch, J. J.; Kovacs, C. A.; Rhee, S.-G. J. Organomet. Chem. 1974, 65, 289-301. See also: (b) Yang, J.; Dudley, G. B. J. Org. Chem. 2009, 74, 7998-8000. (c) Gao, G.; Gu, F.-L.; Jiang, J.-X.; Jiang, K.; Sheng, C.-Q.; Lai, G.-Q.; Xu, L.-W. Chem. Eur. J. 2011, $17,2698-2703$.

(7) Barluenga, J.; Fañanás, F. J.; Sanz, R.; Marcos, C.; Trabada, M. Org. Lett. 2002, 4, 1587-1590.

(8) Sanz, R.; Miguel, D.; Martínez, A.; Pérez, A. J. Org. Chem. 2006, 71, 4024-4027.

(9) By studying the o-lithiation of benzyl fluorophenyl ethers, a partial metalation of the benzylic position of 1a was observed: Chodakowski, J.; Kliś, T.; Serwatowski, J. Tetrahedron Lett. 2005, 46, 1963-1965.

(10) See Supporting Information for a detailed study of the $\alpha$ lithiation of ether $\mathbf{1 a}$.

(11) Increasing the reaction temperature over $-35^{\circ} \mathrm{C}$ to force complete lithiation leads to the competitive formation of diarylmethanol 3e derived from [1,2]-Wittig rearrangement.

(12) Nevertheless, when an aliphatic ester such as ethyl isobutyrate was used, the reaction resulted in a mixture of the corresponding ketone and tertiary alcohol. 
(13) (a) De Luca, L.; Nieddu, G.; Porcheddu, A.; Giacomelli, G. Curr. Med. Chem. 2009, 6, 1-20. (b) Yeung, K.-S.; Yang, Z.; Peng, X.-S.; Hou, X.-L. Prog. Heterocycl. Chem. 2011, 22, 181-216.

(14) See, for instance: (a) Nakamura, I.; Mizushima, Y.; Yamamoto, Y. J. Am. Chem. Soc. 2005, 127, 15022-15023. (b) Fürstner, A.; Davies, P. W. J. Am. Chem. Soc. 2005, 127, 15024-15025. (c) Sakiyama, N.; Noguchi, K.; Tanaka, K. Angew. Chem. Int. Ed. 2012, 51, 5976-5980.

(15) See, for instance: (a) Shen, Z.; Dong, V. M. Angew. Chem. Int. Ed. 2009, 48, 784-786. (b) Ma, X.; Feifei, W.; Yi, X.; Wang, H.; Chen, W. Chem. Commun. 2015, 51, 6862-6865. (c) Hu, M.; Song, R.-J.; Li, J.-H. Angew. Chem. Int. Ed. 2015, 54, 608-612.

(16) (a) Kanazawa, C.; Goto, K.; Terada, M. Chem. Commun. 2009, 5248-5250. (b) Hu, J.; Wu, L.-Y.; Wang, X.-C.; Hu, Y.-Y.; Niu, Y.-N.; Liu, X.-Y.; Yang, S.; Liang, Y.-M. Adv. Synth. Catal. 2010, 352, 351-356. (c) Chen, P.-Y.; Wang, T.-P.; Huang, K.-S.; Kao, C.-L.; Tsai, J.-C.; Wang, E.-C. Tetrahedron 2011, 67, 9291-9297. (d) Grimaldi, T. B.; Back, D. F.; Zeni, G. J. Org. Chem. 2013, 78, 11017-11031.

(17) Fañanás, F. J.; Sanz, R. Intramolecular Carbolithiation Reactions. In The Chemistry of Organolithium Compounds; Rappoport, Z., Marek, I., Eds.; The Chemistry of Functional Groups; Rappoport, Z., Series Ed.; Wiley \& Sons: Chichester, 2006; Vol. 2, Chapter 4, pp
295-379. For our previous work in this field: (a) Barluenga, J.; Fañanás, F. J.; Sanz, R.; Marcos, C. Org. Lett. 2002, 4, 2225-2228. (b) Barluenga, J.; Fañanás, F. J.; Sanz, R.; Marcos, C. Chem. Eur. J. 2005, 11, 5397-5407. (c) Sanz, R.; Ignacio, J. M.; Rodríguez, M. A.; Fañanás, F. J.; Barluenga, J. Chem. Eur. J. 2007, 13, 4998-5008.

(18) See Supporting Information for further details

(19) Bailey, W. F.; Ovaska, T. V. J. Am. Chem. Soc. 1993, 115, 3080-3090.

(20) Double bond configurations were determined by NOESY experiments with the corresponding non-deuteriated $(E=H)$ derivatives 12 (see Supporting Information).

(21) (a) Fressigné, C.; Girard, A.-L.; Durandetti, M.; Maddaluno, J. Angew. Chem. Int. Ed. 2008, 47, 891-893. (b) Lhermet, R.; Ahmad, M.; Fressigné, C.; Durandetti, M.; Maddaluno, J. Chem. Eur. J. 2014, 20, 10249-10254

(22) (a) Fressigné, C.; Lhermet, R.; Girard, A.-L.; Durandetti, M.; Maddaluno, J. J. Org. Chem. 2013, 78, 9659-9669. (b) Lhermet, R.; Ahmad, M.; Hauduc, C.; Fressigné, M. Durandetti, M.; Maddaluno, J. Chem. Eur. J. 2015, 21, 8105-8111.

(23) Vinyllithium intermediates $\mathbf{1 1 b}, \mathbf{c}$ did not isomerize at $\mathrm{rt}$ before undergoing decomposition after extended reaction time. 